\title{
Measurement of Postpartum Blood Loss Using a New Two - Set Liquid Collection Bag for Vaginal Delivery: A Prospective, Randomized, Case Control Study
}

\section{Fang Wang}

Zhejiang University School of Medicine Women's Hospital

\section{Nanjia Lu}

Zhejiang University School of Medicine Women's Hospital

\section{Xiaofeng Weng}

Zhejiang University School of Medicine Women's Hospital

\section{Yanping Tian}

Zhejiang University School of Medicine Women's Hospital

\section{Shiwen Sun}

Zhejiang University School of Medicine Women's Hospital

Baohua Li ( $\square$ lbh19787@zju.edu.cn )

Zhejiang University School of Medicine Women's Hospital https://orcid.org/0000-0002-2205-3248

\section{Research article}

Keywords: Postpartum hemorrhage, Liquid collection bag, Vaginal delivery, Measured blood loss, Accuracy

Posted Date: August 3rd, 2020

DOI: https://doi.org/10.21203/rs.3.rs-41858/v1

License: (9) This work is licensed under a Creative Commons Attribution 4.0 International License. Read Full License

Version of Record: A version of this preprint was published at Medicine on May 14th, 2021. See the published version at https://doi.org/10.1097/MD.0000000000025906. 


\section{Abstract}

Background Postpartum hemorrhage (PPH) is a major obstetric complication, and the real-time measurement of blood loss is important in the management and treatment of PPH. We designed a new two-set liquid collection bag (TSLCB) for measuring postpartum blood loss in vaginal delivery. The aim of this study was to evaluate the effectiveness of the TSLCB in separating the blood from the amniotic fluid during vaginal delivery and in determining the accuracy of the measured postpartum blood loss.

Methods A prospective, randomized, case control study was conducted in the Women's Hospital, Zhejiang University School of Medicine, from March 2018 to April 2018. Sixty single pregnant women with spontaneous labor at 37-41 weeks without maternal complications were randomly divided into the experimental and control groups. The TSLCB was used to evaluate separately the amount of blood and amniotic fluid. For the control group, visual estimation and traditional plastic blood-collecting consumables were used to estimate the amount of postpartum blood loss. The measured blood loss between the two groups was compared, and the association of the measured blood loss with various clinical lab indices and vital signs was investigated.

Results The TSLCB (the experimental group) improved the detection of the measured blood loss compared with visual estimation and the traditional method (the control group) $(p<0.05)$. In the experimental group, correlation analysis showed that the measured blood loss at delivery and within $24 \mathrm{~h}$ of delivery was significantly associated with the decreased hemoglobin level, red blood cell count, and hematocrit level of patients $(r=-0.574,-0.455,-0.437 ; r=0 .-595,-0.368,-0.374 ; p<0.05)$. In the control group, only the measured blood loss within $24 \mathrm{~h}$ of delivery was associated with the decreased hemoglobin level $(r=-0.395, p<0.05)$. No blood transfusion and plasma expanders were required in the treatment of PPH for both groups.

Conclusions The TSLCB can be used to accurately measure the postpartum blood loss in vaginal delivery by medical personnel.

Trial registration: This trial was registered with Chinese Clinical Trial Registry (ChiCTR): ChiCTR-IOR17012453, 23 August 2017.

\section{Background}

Postpartum hemorrhage (PPH), as one of the leading causes of maternal mortality, endangers the lives of mothers due to massive bleeding within a short period of time [1]. PPH is defined as blood loss of $500 \mathrm{~mL}$ or more within the first $24 \mathrm{~h}$ after delivery, regardless of the mode of delivery (cesarean or vaginal) [2]. Furthermore, PPH is considered severe when the amount of blood loss is more than $1,000 \mathrm{~mL}$. Approximately 289,000 women died due to pregnancy complications in 2013; of these, $27 \%$ died from severe PPH [3]. The rescued mothers may also suffer from various sequelae, such as Sheehan's syndrome or hysterectomy, which may cause physical and mental health problems to mothers and their families [4]. 
An underestimation of postpartum blood loss delays the diagnosis and treatment of PPH, which can cause severe consequences, even death. Individual risk factors have been identified; however, studies have reported that they cannot accurately predict the occurrence of PPH $[5,6]$. Presently, decreasing the prevalence of $\mathrm{PPH}$ remains a challenge $[7,8]$, and the accurate measurement of postpartum blood loss is critical for the diagnosis, prevention, and treatment of $\mathrm{PPH}$, especially in severe cases [9].

Most studies have investigated postpartum blood loss during childbirth. Several methods have been used to assess PPH, particularly after vaginal delivery, that include visual estimation, gravimetric measurement, direct measurement, photometry and other methods such as the shock index method, red blood cell counts, and hemoglobin levels [10]. However, there are few tools that can collect and measure the amount of postpartum blood loss [11], especially during vaginal delivery, because blood mixes with amniotic fluid during childbirth.

We designed a new two-set liquid collection bag (TSLCB) for vaginal delivery (patent no. 20162 1484515.4 , China), which allows the blood and the amniotic fluid to be collected in separate transparent plastic bags, thereby allowing us to accurately measure the amount of postpartum blood loss. We believe that excessive blood loss in vaginal delivery will initiate the response protocol, which can effectively reduce the incidence of serious maternal complications induced by PPH.

\section{Methods}

\section{Study design}

A prospective, randomized, case control study was performed in the maternity ward of the Women's Hospital, Zhejiang University School of Medicine from March 2019 to April 2019. In brief, 60 singleton pregnant women with spontaneous labor at 37-41 weeks without maternal complications were randomly divided into the experimental or the control group.

The study was approved by the Institutional Review Board of the Women's Hospital, Zhejiang University School of Medicine (approval no. 20160095). All patients provided written informed consent, and the study was conducted in accordance with the Declaration of Helsinki. This study adheres to CONSORT guidelines.

\section{Patients and eligibility}

The criteria for inclusion were as follows: an age of 18-35 years; a gestational age of 37-41 weeks; single birth; cephalic presentation; no complications during pregnancy; and a willingness to participate in this study. The exclusion criteria were as follows: a history of bleeding-related disorders (i.e., primary coagulopathy or blood-clotting disorders); fetal distress; third-degree (or above) serious perineal lacerations; postpartum complications, except postpartum hemorrhage; a history of sexually transmitted diseases or infectious diseases; and a history of vaginal inflammatory diseases.

\section{Randomization and Intervention}


When pregnant women admission to the delivery room, midwives assessed whether they were eligible to participate in the trial by checking that the inclusion criteria were met. To guarantee that the allocation to groups remained concealed until women were admitted to the study.

Simple randomization was used to allocate study participants. Opaque, sealed and consecutively numbered envelopes containing randomization assignment were randomly mixed and placed in a box. Each envelope contained a data collection sheet. When the woman was admitted in active labor, the midwife asked whether the woman was still willing to participate and if so, drew an envelope in strict number succession. The randomization was $1: 1$, and the preparation of the envelopes containing the information were carried out by a researcher who was not directly involved with the study.

For the experimental group, a new TSLCB was used to collect blood and amniotic fluid separately, and to keep the delivery area sterile. The amount of blood was subsequently measured. For the control group, visual estimation and traditional plastic blood-collecting consumables with volume markings (maximum volume, $500 \mathrm{~mL}$ ) were used. In both groups, gauze and nursing pads used within $24 \mathrm{~h}$ of delivery were also weighed, and the total blood loss was determined as follows: volume $(\mathrm{mL})=$ weight $(\mathrm{g}) / 1.05$. To ensure the authenticity and reliability of the data, postpartum blood loss was observed, evaluated, and recorded by the same midwives (FW, XFW, YPT, and SWS). The trial seems to be terminated when the pregnant women occurred severe obstetric complications such as amniotic fluid embolism, disseminated intravascular coagulation, uterine rupture, and so on.

\section{Postpartum blood loss measurement techniques}

Based on the common delivery positions, such as lithotomy, sitting, and lateral positions, we designed a new TSLCB to measure the amount of postpartum blood loss for vaginal delivery. The design of the TSLCB is shown in Figure 1. Before delivery, we placed hip pads under the woman's buttocks, covered the leg pads at her right and left thighs, and then taped and fixed the TSLCB. We adjusted the position of the liquid collection bag to ensure that the opening of the bag was under the vaginal orifice (Fig. 2a). In cases of perineotomy, blood from the wound, which is often unaccounted for, was collected in the inner bag before childbirth, and the amount of blood was carefully measured. Amniotic fluid was collected in the inner bag from the time of the birth of the fetus to the delivery of the placenta (Fig. 2b). Lastly, we removed the inner bag (Fig. 2c) and used the outer bag to collect and measure the postpartum blood loss until active bleeding stopped (Fig. 2d).

\section{Data collection}

All patients completed the demographic and obstetric questionnaire on the day of admission. A computerized obstetric database was also used. Data on a range of demographic characteristics and neonatal outcomes were collected. For both groups, blood samples were collected on the day of admission and $24 \mathrm{~h}$ after delivery.

\section{Primary outcomes}


The primary outcomes were heart rate and systolic blood pressure, as well as the volume of amniotic fluid and the amount of postpartum blood loss, at delivery and within $24 \mathrm{~h}$ of delivery. The hemoglobin level, red blood cell count, hematocrit level, platelet count, and D-dimer level of patients before delivery and within $24 \mathrm{~h}$ of delivery were separately assessed.

\section{Statistical analysis}

All statistical analyses were performed using the Statistical Package for the Social Sciences Version 21.0 (SPSS Inc., Chicago IL, USA). Descriptive analyses were carried out by calculating the frequencies and percentages for categorical variables; the means \pm standard deviation for continuous variables, if normally distributed; or the medians (ranges), if not normally distributed. Student's $t$-test, chi-square test, Fisher's exact test and the Mann-Whitney $U$ test were used to compare data between the groups. Pearson correlation was used to analyze the association between the measured postpartum blood loss and the changes in hemoglobin level, red blood cell count, hematocrit level, platelet count, D-dimer level, and shock index of patients. The correlation coefficient was reported using Pearson's correlation $r$ and $p$ values. All statistical tests were two-sided, and $p$-values $<0.05$ were considered statistically significant.

\section{Results}

Sixty participants meeting the inclusion and exclusion criteria were enrolled in this study. Patients were randomly divided into the experimental and control groups. The demographic and obstetric characteristics, as well as the neonatal outcomes, are presented in Table 1. There were no significant differences in age (31.47 \pm 4.27 vs $30.57 \pm 3.95, p>0.05)$ and body mass index (BMl, $26.15 \pm 2.30$ vs $25.06 \pm 1.99, p>0.05$ ) between the groups. There was no significant difference in parity between the groups. For the experimental group, there were 15 out of 30 primiparas; for the control group, there were 10 out of 30 primiparas. The mean gestational age was $39.64 \pm 0.97$ and $39.21 \pm 1.09$ weeks for the experimental and control groups, respectively $(p>0.05)$. Thirty $(100.0 \%)$ patients in the experimental group had spontaneous vaginal deliveries, whereas 1 (3.3\%) patient in the control group had a delivery by forceps. Twenty-eight (93.3\%) patients in the experimental group and 29 (96.7\%) patients in the control group selected the lithotomy position for delivery, with few patients choosing the sitting or lateral position $(p>0.05)$. In addition, $13(43.3 \%)$ and 11 (36.7\%) patients in experimental and control groups underwent episiotomy, respectively, and there was no significant difference between the groups. Moreover, there were no significant differences in the first, second, and third stages of labor between the groups [385.00 (89.00-1,060.00) vs 350.00 (70.00-1,135.00), 31.00 (5.00-117.00) vs 30.00 (1.00-146.00), 5.00 (1.00$14.00)$ vs. $5.00(1.00-15.00)$, respectively, $p>0.05]$. The Apgar score at 1 and 5 minutes was $10(8-10)$ vs. $10(9-10), 10(9-10)$ vs $10(10-10)$, respectively $(p>0.05)$, and the birth weight was $3,516.00 \pm$ $494.98 \mathrm{~g}$ vs. $3,300.67 \pm 398.44 \mathrm{~g}(p>0.05)$ between the groups.

Table 2 shows that there was no significant difference in the amount of amniotic fluid at delivery between the experimental and control groups [300.00 (100.00-1,200.00) mL vs $300.00(80.00-800.00) \mathrm{mL}$, respectively; $p=0.982]$. The mean measured blood loss at delivery was $372.00(150.00-900.00) \mathrm{mL}$ in 
the experimental group and $200.00(100.00-600.00) \mathrm{mL}$ in the control group $(p=0.000)$, demonstrating a significant increase in the experimental group compared with the control group. Within 24 hours of delivery, the mean measured blood loss was $536.00(220.00-1,030.00) \mathrm{mL}$ in the experimental group and $378.50(170.00-1,110.00) \mathrm{mL}$ in the control group $(p=0.003)$. The rate of PPH was $53.33 \%$ and $16.67 \%$ in experimental and control groups, and the difference between the groups was significant $(p=0.003)$. However, there was no significant difference in the rate of severe PPH between the groups $(6.67 \%$ vs $3.33 \%, p=1.000$ ), indicating that the TSLCB improved the detection of measured postpartum blood loss in the experimental group compared with the control group. As there were no severe PPH cases in this study, blood transfusions and plasma expanders were not needed.

The clinical lab indices and vital signs of the two groups at pre- and post-delivery are shown in Supplementary Table 1. There were no significant differences in the hemoglobin level, red blood cell count, hematocrit level, platelet count, and D-dimer level before delivery and $24 \mathrm{~h}$ after delivery in the experimental and control groups $(p=0.266,0.290,0.260,0.860,0.988 ; p=0.138,0.261,0.213,0.590$, $0.767)$. In addition, there was no difference in the shock index at delivery, $1 \mathrm{~h}$ after delivery, and $2 \mathrm{~h}$ after delivery between the groups $(p=0.399,0.947,0.647)$.

In Supplementary Table 2, we analyzed the correlation between the measured blood loss and various clinical lab indices and vital signs. In the control group, there was no association between the measured blood loss and the hemoglobin level, red blood cell count, hematocrit level, and shock index at delivery ( $p$ $>0.05$ ). As shown in Figure 3 , within $24 \mathrm{~h}$ of delivery the measured blood loss was negatively correlated with the decreased hemoglobin level in the control group $(r=-0.395, p<0.05)$, whereas the measured blood loss in the experimental group at delivery and within $24 \mathrm{~h}$ of delivery was significantly correlated with the decreased hemoglobin level, red blood cell count, and hematocrit level $(r=-0.574,-0.455,-0.437 ; r$ $=-0.595,-0.368,-0.374 ; p<0.05)$. However, there was no correlation with the shock index $(p>0.05)$. These results indicate that the TSLCB can accurately measure postpartum blood loss in vaginal delivery.

\section{Discussion}

In this prospective, randomized, case control study, we report that a new TSLCB significantly improved the detection of the measured blood loss compared with the visual estimation method. Equally important, the measured blood loss using the TSLCB correlated with the decreased hemoglobin level, red blood cell count, and hematocrit level of patients at delivery and within $24 \mathrm{~h}$ of delivery, suggesting that TSLCB is a useful tool for accurately measuring blood loss due to PPH in vaginal delivery.

$\mathrm{PPH}$ is a serious complication at delivery, whose prognosis is related to the volume and the rate of blood loss as well as the rescue time [12]. However, the measurement of postpartum blood loss is difficult, particularly in vaginal delivery. Several studies have reported overestimations of blood loss at low volumes and underestimations at high volumes after vaginal delivery using visual estimation methods [13]. Currently, there are no reliable tools to measure the amount of postpartum blood loss $[10,14,15]$. Tourne et al. used a plastic bag to collect and measure the volume of blood loss after delivery and 
investigated the correlation between the bag's volume and hemoglobin and hematocrit levels. The authors showed that the collection bag can facilitate the diagnosis of PPH in the delivery room [16]. However, Zhang et al. found that the collection bag in vaginal delivery did not reduce the rate of severe PPH compared with the visual estimation of postpartum blood loss [8]. Therefore, the American Congress of Obstetricians and Gynecologists (ACOG) and the Royal College of Obstetricians and Gynecologists (RCOG) do not recommend the use of tools (such as the graduated collection bag) to estimate blood loss in vaginal delivery $[17,18]$. In the present study, we designed a new TSLCB and examined its accuracy in the measurement of postpartum blood loss for vaginal delivery. Our data showed that the measured blood loss at delivery and within $24 \mathrm{~h}$ of delivery was significantly greater in the TSCLB group than that in the control group, although there were no significant differences in demographic and obstetric characteristics between the groups. As there were no severe PPH cases in this study, blood transfusions and plasma expanders were not needed. Furthermore, we used other parameters of bleeding, such as the hemoglobin level, red blood cell count, hematocrit level, and shock index, to evaluate the accuracy of the TSLCB in measuring the amount of postpartum blood loss in vaginal delivery. We found that the blood loss at delivery and within $24 \mathrm{~h}$ of delivery in the TSCLB group was significantly correlated with the decreased hemoglobin level, red blood cell count, and hematocrit level $(r=-0.574,-0.455,-0.437 ; r=$ $0 .-595,-0.368,-0.374 ; p<0.05)$. However, in the control group, only the blood loss within $24 \mathrm{~h}$ of delivery was correlated with the decreased hemoglobin level $(r=-0.395, p<0.05)$. The results suggested that the amount of measured blood loss, as determined by the TSCLB, was similar to the actual amount of blood loss, indicating that the TSCLB was more accurate in the measurement of blood loss compared to the visual estimation method. Previous studies have reported that blood collection bags can improve the accuracy of the measured blood loss [7, 19-21]. The French College of Obstetricians and Gynecologists (CNGOF) recommend that medical professionals determine whether a collection bag should be used as a tool to evaluate postpartum blood loss [22]. PPH is a complication in 5 to $10 \%$ of all deliveries. The traditional definitions of PPH serve as an estimated blood loss in excess of $500 \mathrm{~mL}$ after a vaginal delivery or a loss of greater than $1,000 \mathrm{~mL}$ after a cesarean section. In our study, the incidence of PPH may be $16.67 \%$ using visual estimation; interesting, we found that the rate of PPH in the TSCLB group was much higher than that in the control group $(53.33 \%$ vs $16.67 \%, p=0.003)$. Based on the accuracy of estimated PPH using TSCLB method, we wonder whether traditional method caused the significant underestimations of blood loss after vaginal delivery. Recently, ACOG redefines PPH as cumulative blood loss greater than or equal to $1,000 \mathrm{~mL}$ regardless of route of delivery [17]. We indeed agree with ACOG's definition for PPH. Additionally, our results showed that there was no statistical difference in the incidence of severe PPH, indicating that the TSCLB is useful in the early detection and intervention of $\mathrm{PPH}$ and in the prevention of severe PPH.

In our study, there were three merits of using the TSCLB to measure the amount of blood loss in vaginal delivery. First, it was extremely difficult to measure the actual amount of blood loss by visual estimation methods, because blood and amniotic fluid are often mixed during childbirth [23]. We designed the new TSLCB for vaginal delivery, which allowed the blood to be separated from the amniotic fluid by collecting the components in two transparent plastic bags. Secondly, perineotomy was sometimes needed for 
vaginal delivery, and the amount of blood from the wound was often greatly underestimated. Using the TSCLB, we could collect blood from the wound in the inner bag before childbirth and objectively measure the amount of postpartum blood loss as well as reduce the environmental pollution in the delivery room. Finally, the reading of the plastic blood collection bag was only an estimation, and the maximum volume of the bag is $500 \mathrm{~mL}$ [24]. Therefore, blood will be lost when the volume exceeds $500 \mathrm{~mL}$, leading to a significant underestimation of postpartum blood loss. The TSCLB solved this issue because of the presence of a drain valve. Taken together, our results indicated that the TSLCB could accurately determine the amount of blood loss in vaginal delivery by medical personnel.

The current study had several limitations. Firstly, our sample size was small, so future studies should include more participants to confirm our results. Secondly, this was a single-center study, and women were recruited from only one hospital. Therefore, our results may be biased. Finally, the researchers were not blinded to the data of the patients. However, the researchers were aware of the importance of objectivity when collecting data.

\section{Conclusions}

The accurate measurement of blood loss in vaginal delivery is critical for the diagnosis, prevention, and treatment of PPH. We designed a new TSLCB that could accurately measure the amount of blood loss in vaginal delivery. It could also reduce the environmental pollution in the delivery room and help medical personnel initiate the response protocol to reduce the incidence of serious maternal complications caused by PPH.

\section{Abbreviations}

PPH: Postpartum Hemorrhage

TSLCB: Two-set Liquid Collection Bag

ACOG: American Congress of Obstetricians and Gynecologists

RCOG: Royal College of Obstetricians and Gynecologists

CNGOF: French College of Obstetricians and Gynecologist

\section{Declarations}

\section{Ethics approval and consent to participate}

The study was approved by the Institutional Review Board of the Women's Hospital, Zhejiang University School of Medicine (approval no. 20160095). Human Participants and/or Animals rights statement: this article does not contain any studies with animals performed by any of the authors. Written informed consent for participation was obtained from each patient.All procedures performed in studies involving 
human participants were in accordance with the ethical standards of the institutional and/or national research committee and with the 1964 Helsinki Declaration and its later amendments or comparable ethical standards. Informed consent was obtained from all participants included in the study.

\section{Consent for publication}

Not applicable.

\section{Availability of data and materials}

The datasets used and/or analysed during the current study are available from the corresponding author on reasonable request.

\section{Competing interests}

The authors declare that they have no competing interests.

\section{Funding}

This study was supported by the Medical and Health Science and Technology Plan Project of Zhejiang Province (Grant No. 2017PY005 and Grant No. 2019PY040). The Department has no conflict of interests related to the trial.

\section{Author contributions}

$\mathrm{BHL}$ contributed to the study conception, the study design, and the drafting of the manuscript. FW contributed to the data collection and analysis and the writing of the manuscript. FW, NJL, XFW, YPT and SWS contributed to the data acquisition and the statistical analysis. All authors read and approved the final manuscript.

\section{Acknowledgements}

Our deep thanks goes to Women's Hospital, Zhejiang University School of Medicine for allowing us to conduct this study. We would sincerely like to acknowledge the help of all midwives and doctors, as well as all the pregnant women who participated in the study. We further thank International Science Editing (http://www.internationalscienceediting.com) for editing this manuscript.

\section{References}

1. Say L, Chou D, Gemmill A, Tuncalp O, Moller AB, Daniels J, et al. Global causes of maternal death: a WHO systematic analysis. Lancet Glob Health. 2014;2(6):323-33.

2. Chandraharan E, Krishna A. Diagnosis and management of postpartum haemorrhage. BMJ. 2017;358:3875. 
3. World Health Organization. Geneva:World Health Organization. 2015. http://www.who.int/mediacentre/news/releases/2015/voluntary-blood-donors/zh/. Accessed 11 Jun 2015.

4. Lepine SJ, Geller SE, Pledger M, Lawton B, MacDonald EJ. Severe maternal morbidity due to obstetric haemorrhage: Potential preventability. Aust N Z J Obstet Gynaecol. 2019;60(2):212-17.

5. Nyflot LT, Sandven I, Stray-Pedersen B, Pettersen S, Al-Zirqi I, Rosenberg M, et al. Risk factors for severe postpartum hemorrhage: a case-control study. BMC Pregnancy Childbirth. 2017;17(1):17.

6. Andrikopoulou M, D'Alton ME. Postpartum hemorrhage: early identification challenges. Semin Perinatol. 2019;43(1):11-7.

7. Ambardekar S, Shochet T, Bracken H, Coyaji K, Winikoff B. Calibrated delivery drape versus indirect gravimetric technique for the measurement of blood loss after delivery: a randomized trial. BMC Pregnancy Childbirth. 2014;14:276.

8. Zhang WH, Deneux-Tharaux C, Brocklehurst P, Juszczak E, Joslin M, Alexander S, et al. Effect of a collector bag for measurement of postpartum blood loss after vaginal delivery: cluster randomised trial in 13 European countries. BMJ. 2010;340:293.

9. Hancock A, Weeks AD, Lavender DT. Is accurate and reliable blood loss estimation the 'crucial step' in early detection of postpartum haemorrhage: an integrative review of the literature. BMC Pregnancy Childbirth. 2015;15:230.

10. Diaz V, Abalos E, Carroli G. Methods for blood loss estimation after vaginal birth. Cochrane Database Syst Rev. 2018;9:CD010980.

11. Quantitative Blood Loss in Obstetric Hemorrhage: ACOG COMMITTEE OPINION, Number 794. Obstet Gynecol. 2019;134(6):150-6.

12. Higgins N, Patel SK, Toledo P. Postpartum hemorrhage revisited: new challenges and solutions. Curr Opin Anaesthesiol. 2019;32(3):278-84.

13. Legendre G, Richard M, Brun S, Chancerel M, Matuszewski S, Sentilhes L. Evaluation by obstetric care providers of simulated postpartum blood loss using a collector bag: a French prospective study. $\mathrm{J}$ Matern Fetal Neonatal Med. 2016;29(21):3575-81.

14. Schorn MN. Measurement of blood loss: review of the literature. J Midwifery Womens Health. 2010;55(1):20-7.

15. Kahr MK, Brun R, Zimmermann R, Franke D, Haslinger C. Validation of a quantitative system for realtime measurement of postpartum blood loss. Arch Gynecol Obstet. 2018;298(6):1071-7.

16. Tourne G, Collet F, Lasnier P, Seffert P. [Usefulness of a collecting bag for the diagnosis of postpartum hemorrhage]. J Gynecol Obstet Biol Reprod (Paris). 2004;33(3):229-34.

17. Committee on Practice B-O. Practice Bulletin No. 183: Postpartum Hemorrhage. Obstet Gynecol. 2017;130(4):168-86.

18. Royal College of Obstetrician and Gynaecol-ogists. Postpartum hemorrhage: prevention and management. April 2011. 
http://www.rcog.org.uk/womens-health/clinical-guidance/prevention-and-management-postpartumhaemorrhage-green-top-52. Accessed 1 Nov 2013.

19. Patel A, Goudar SS, Geller SE, Kodkany BS, Edlavitch SA, Wagh K, et al. Drape estimation vs. visual assessment for estimating postpartum hemorrhage. Int J Gynaecol Obstet. 2006;93(3):220-4.

20. Lumbreras-Marquez MI, Reale SC, Carusi DA, Robinson JN, Scharf N, Fields KG, et al. Introduction of a Novel System for Quantitating Blood Loss After Vaginal Delivery: A Retrospective Interrupted Time Series Analysis With Concurrent Control Group. Anesth Analg. 2020;130(4):857-68.

21. Al Kadri HM, Al Anazi BK, Tamim HM. Visual estimation versus gravimetric measurement of postpartum blood loss: a prospective cohort study. Arch Gynecol Obstet. 2011;283(6):1207-13.

22. Sentilhes L, Vayssiere C, Deneux-Tharaux C, Aya AG, Bayoumeu F, Bonnet MP, et al. Postpartum hemorrhage: guidelines for clinical practice from the French College of Gynaecologists and Obstetricians (CNGOF): in collaboration with the French Society of Anesthesiology and Intensive Care (SFAR). Eur J Obstet Gynecol Reprod Biol. 2016;198:12-21.

23. Woiski MD, Scheepers HC, Liefers J, Lance M, Middeldorp JM, Lotgering FK, et al. Guideline-based development of quality indicators for prevention and management of postpartum hemorrhage. Acta Obstet Gynecol Scand. 2015;94(10):1118-27.

24. Lemee J, Scalabre A, Chauleur C, Raia-Barjat T. Visual estimation of postpartum blood loss during a simulation training: A prospective study. J Gynecol Obstet Hum Reprod. 2020;49(4):101673.

\section{Tables}


Table 1

Demographic, obstetric characteristics and neonatal outcomes of the patients included in the study

\begin{tabular}{|c|c|c|c|}
\hline Characteristics & $\begin{array}{l}\text { Experimental group } \\
(n=30)\end{array}$ & $\begin{array}{l}\text { Control group } \\
(n=30)\end{array}$ & $p$ \\
\hline Age (years) & $31.47 \pm 4.27$ & $30.57 \pm 3.95$ & 0.401 \\
\hline Body mass index $(\mathrm{kg} / \mathrm{m} 2)$ & $26.15 \pm 2.30$ & $25.06 \pm 1.99$ & 0.055 \\
\hline Parity: n (\%) & & & 0.190 \\
\hline Nulliparous & $15(50.0)$ & $20(66.7)$ & \\
\hline Multiparous & $15(50.0)$ & $10(33.3)$ & \\
\hline Gestational age (weeks) & $39.64 \pm 0.97$ & $39.21 \pm 1.09$ & 0.112 \\
\hline Delivery characteristics: $\mathbf{n}(\%)$ & & & 1.000 \\
\hline Spontaneous vaginal delivery & $30(100.0)$ & $29(96.7)$ & \\
\hline Forceps delivery & $0(0.0)$ & $1(3.3)$ & \\
\hline Delivery position: $\mathrm{n}(\%)$ & & & 1.000 \\
\hline Lithotomy position & 28(93.3) & $29(96.7)$ & \\
\hline Sitting position & 1(3.3) & $0(0.0)$ & \\
\hline Lateral position & $1(3.3)$ & $1(3.3)$ & \\
\hline Episiotomy performed: n (\%) & & & 0.598 \\
\hline Yes & 13(43.3) & $11(36.7)$ & \\
\hline No & 17(56.7) & 19(63.3) & \\
\hline \multicolumn{4}{|l|}{ Time of labor (min) } \\
\hline The first stage of labor & $385.00(89.00-1,060.00)$ & $350.00(70.00-1,135.00)$ & 0.535 \\
\hline The second stage of labor & $31.00(5.00-117.00)$ & $30.00(1.00-146.00)$ & 0.701 \\
\hline The third stage of labor & $5.00(1.00-14.00)$ & $5.00(1.00-15.00)$ & 0.629 \\
\hline \multicolumn{4}{|l|}{ Neonatal outcomes } \\
\hline Apgar score at 1 minute & $10.00(8.00-10.00)$ & $10.00(9.00-10.00)$ & 0.297 \\
\hline Apgar score at 5 minute & $10.00(9.00-10.00)$ & $10.00(10.00-10.00)$ & 0.317 \\
\hline Birth weight (g) & $3,516.00 \pm 494.98$ & $3,300.67 \pm 398.44$ & 0.069 \\
\hline
\end{tabular}


Table 2

Measured amniotic fluid and postpartum blood loss between two groups

\begin{tabular}{|c|c|c|c|}
\hline & Experimental group & Control group & \multirow[t]{2}{*}{$p$} \\
\hline & $(n=30)$ & $(n=30)$ & \\
\hline Measured amniotic fluid at delivery $(\mathrm{mL})$ & $\begin{array}{l}300.00(100.00- \\
1,200.00)\end{array}$ & $300.00(80.00-800.00)$ & 0.982 \\
\hline Measured blood loss at delivery $(\mathrm{mL})$ & $\begin{array}{l}372.00(150.00- \\
900.00)\end{array}$ & $\begin{array}{l}200.00(100.00- \\
600.00)\end{array}$ & 0.000 \\
\hline $\begin{array}{l}\text { Measured blood loss within } 24 \mathrm{~h} \text { of } \\
\text { delivery }(\mathrm{mL})\end{array}$ & $\begin{array}{l}536.00(220.00- \\
1,030.00)\end{array}$ & $\begin{array}{l}378.50(170.00- \\
1,110.00)\end{array}$ & 0.003 \\
\hline Measured blood loss $\geq 500: \mathrm{n}(\%)$ & $16 \rrbracket 53.33 \% \bigotimes$ & $5 \rrbracket 16.67 \% \rrbracket$ & 0.003 \\
\hline Measured blood loss $\geq 1000: n(\%)$ & $2 \varangle 6.67 \% \rrbracket$ & $1 \otimes 3.33 \% \bigotimes$ & 1.000 \\
\hline
\end{tabular}

Figures 


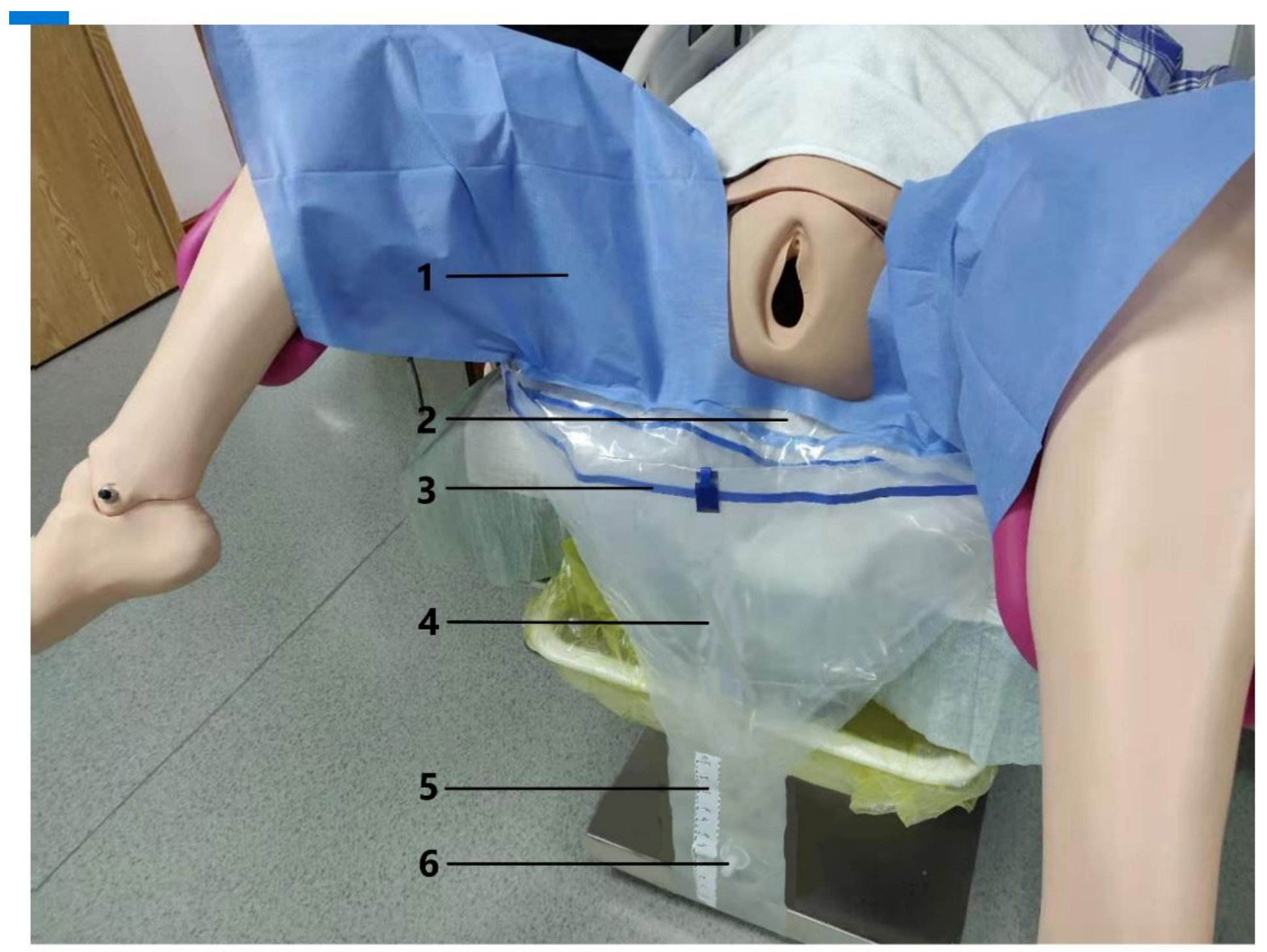

\section{Figure 1}

The design of the TSLCB. Part 1: Leg pads: keeping the sterile state of local leg; Part 2: Hip pad: Blood or amniotic fluid running out easily; Part 3: Bag opening support frame: Keeping the opening of the bag; Part 4: Liquid collecting bag: inner bag and outer bag; Part 5: Scale: the measurement of the amount of blood and amniotic fluid; Part 6: Drain valve. 

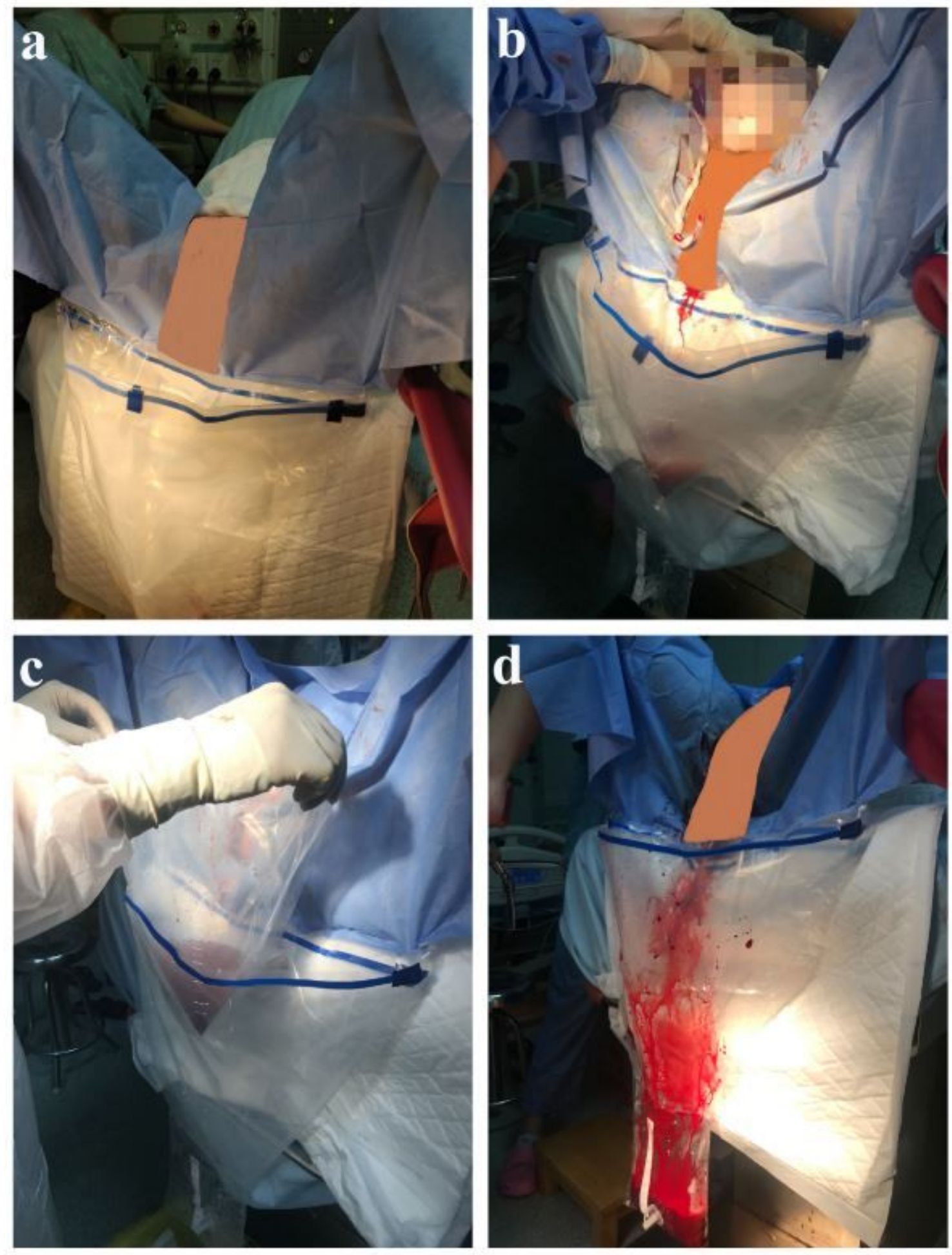

\section{Figure 2}

The procedure of using TSCLB. a: Before delivery, placing hip pads under the woman's buttocks, and covering the leg pads at her right and left thighs. b: In cases of perineotomy, blood from the wound could be collected in the inner bag before childbirth. c: Amniotic fluid would be collected and measured in the inner bag from the time of the birth of the fetus to the delivery of the placenta. d: Blood would be collected and measured until active bleeding stopped. 
a

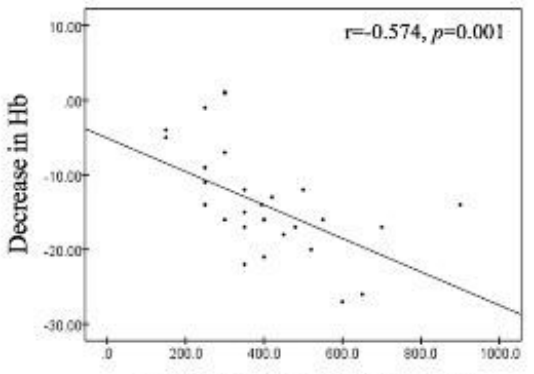

d

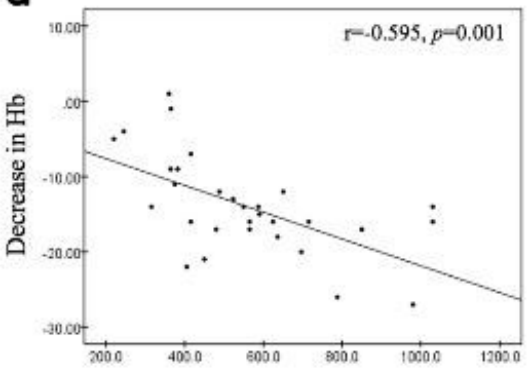

Measured blood loss within $24 \mathrm{~h}$ of delivery b

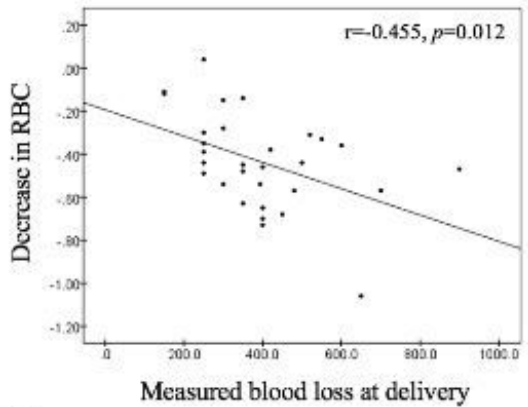

e

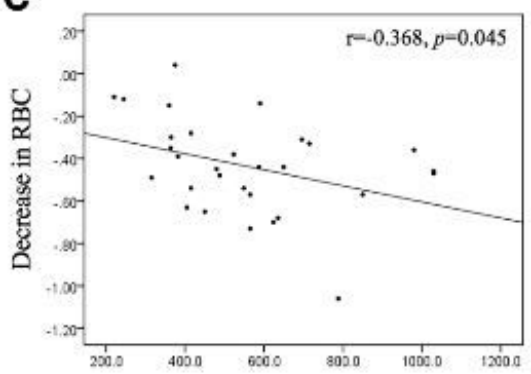

Measured blood loss within $24 \mathrm{~h}$ of delivery
C

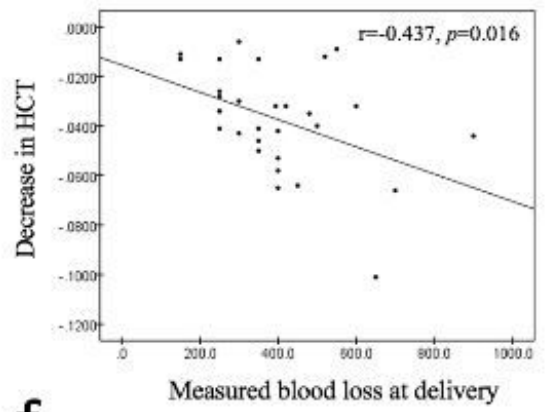

$f$

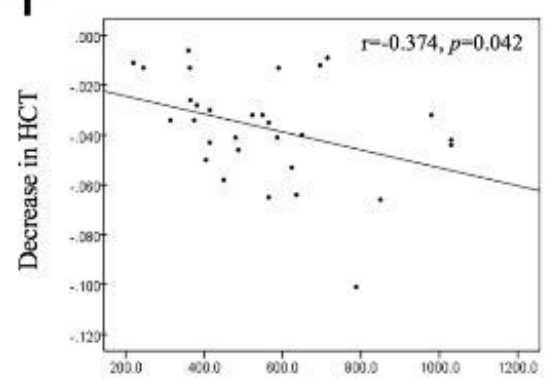

Measured blood loss within $24 \mathrm{~h}$ of delivery

Control group

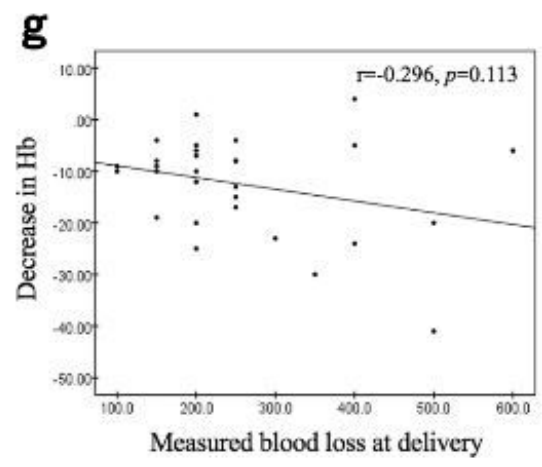

h

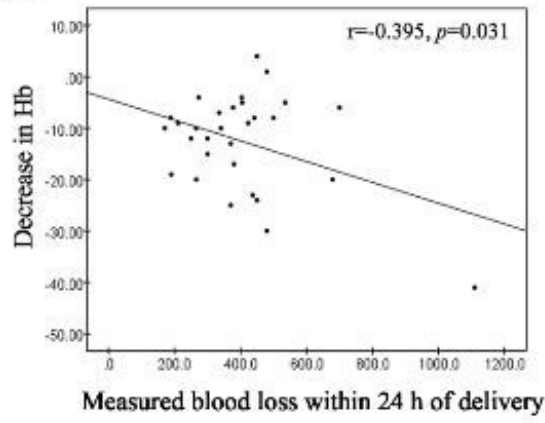

\section{Figure 3}

Significance of the correlation between measured blood loss and various clinical lab indices. The measured blood loss in the experimental group at delivery or within $24 \mathrm{~h}$ of delivery was negatively correlated with the decreased hemoglobin level (a, d), red blood cell count (b, e), and hematokrit level (c, $\mathrm{f})$; whereas in the control group, the measured blood loss at delivery was no correlation with the decreased hemoglobin level $(\mathrm{g})$ but within $24 \mathrm{~h}$ of delivery they had statistical negative correlation $(\mathrm{h})$.

\section{Supplementary Files}

This is a list of supplementary files associated with this preprint. Click to download.

- Supplementarytable1.doc 
- Supplementarytable2.doc

- CONSORT2010Checklist.doc 